Research Article

\title{
Seismic Performance of High-Ductile Fiber-Reinforced Concrete Short Columns
}

\author{
Mingke Deng $(\mathbb{D}$ ) and Yangxi Zhang $(\mathbb{D}$ \\ Department of Civil Engineering, Xi'an University of Architecture and Technology, Xi'an, China \\ Correspondence should be addressed to Yangxi Zhang; 18829588343@163.com
}

Received 30 August 2017; Revised 2 November 2017; Accepted 20 November 2017; Published 28 February 2018

Academic Editor: John Mander

Copyright (C) 2018 Mingke Deng and Yangxi Zhang. This is an open access article distributed under the Creative Commons Attribution License, which permits unrestricted use, distribution, and reproduction in any medium, provided the original work is properly cited.

\begin{abstract}
This study mainly aims to investigate the effectiveness of high-ductile fiber-reinforced concrete (HDC) as a means to enhance the seismic performance of short columns. Six HDC short columns and one reinforced concrete (RC) short column were designed and tested under lateral cyclic loading. The influence of the material type (concrete or HDC), axial load, stirrup ratio, and shear span ratio on crack patterns, hysteresis behavior, shear strength, deformation capacity, energy dissipation, and stiffness degradation was presented and discussed, respectively. The test results show that the RC short column failed in brittle shear with poor energy dissipation, while using HDC to replace concrete can effectively improve the seismic behavior of the short columns. Compared with the RC short column, the shear strength of HDC specimens was improved by $12.6-30.2 \%$, and the drift ratio and the energy dissipation increases were $56.9-88.5 \%$ and $237.7-336.7 \%$, respectively, at the ultimate displacement. Additionally, the prediction model of the shear strength for RC columns based on GB50010-2010 (Chinese code) can be safely adopted to evaluate the shear strength of HDC short columns.
\end{abstract}

\section{Introduction}

Reinforced concrete (RC) short columns are structural members with high lateral stiffness but often failed in shear with low energy dissipation in strong earthquakes [1], which causes serious damage to the structure and great difficulty for the postearthquake repairing. Therefore, investigating practical and effective methods to enhance the seismic behavior of short columns is very important.

Incorporation of fibers into concrete is a feasible method to reduce the brittleness of concrete and improve the seismic behavior of short columns. Research works $[2,3]$ have shown that the steel fiber and polyvinyl alcohol (PVA) fiber incorporated into concrete can improve the seismic performance of short columns. However, with the increase of concrete strength, incorporation of fibers would be of no avail.

High-ductile fiber-reinforced concrete (HDC) $[4,5]$ is a kind of fiber-reinforced cement composites like engineering cementitious composites (ECC) $[6,7]$ and high-performance fiber-reinforced cement composites (HPFRCCs) [8, 9], which shows steady propagation of multiple fine cracks and excellent tensile strain-hardening behavior due to the fiber-bridging effect [6]. Those materials provide a new method to solve the brittleness of concrete; thus, they have been paid more and more attention in structural engineering. Application of fiber-reinforced cement composite materials in beams [10-12], beam-column joints [13,14], slabs [15], and masonry structures $[16,17]$ has been widely studied, while there are limited researches about fiber-reinforced cement composites used in short columns. Research work by $\mathrm{Wu}$ et al. [18] shows that the seismic behavior of steel-reinforced ECC short columns is much better than that of RC columns, while the axial load of the columns in this work is relative low.

The present study investigates the use of HDC as an alternative design of seismic short columns, where the use of the HDC as replacement of concrete is expected to improve the deformation capacity and energy dissipation ability of short columns. Six HDC short columns and one RC short 
TABLE 1: Mix proportion of HDC $\left(\mathrm{kg} / \mathrm{m}^{3}\right)$.

\begin{tabular}{lcccc}
\hline Binder & Sand & Water & PVA fiber & Water reducers \\
\hline $1186 \mathrm{~kg}$ & $427 \mathrm{~kg}$ & $344 \mathrm{~kg}$ & $26 \mathrm{~kg}$ & $8 \mathrm{~kg}$ \\
\hline
\end{tabular}

TABle 2: Properties of PVA fibers.

\begin{tabular}{lcccc}
\hline Fiber type & Length & Diameter & Tensile strength & Tensile modulus \\
\hline PVA & $12 \mathrm{~mm}$ & $0.39 \mu \mathrm{m}$ & $1600 \mathrm{MPa}$ & $40 \mathrm{GPa}$ \\
\hline
\end{tabular}

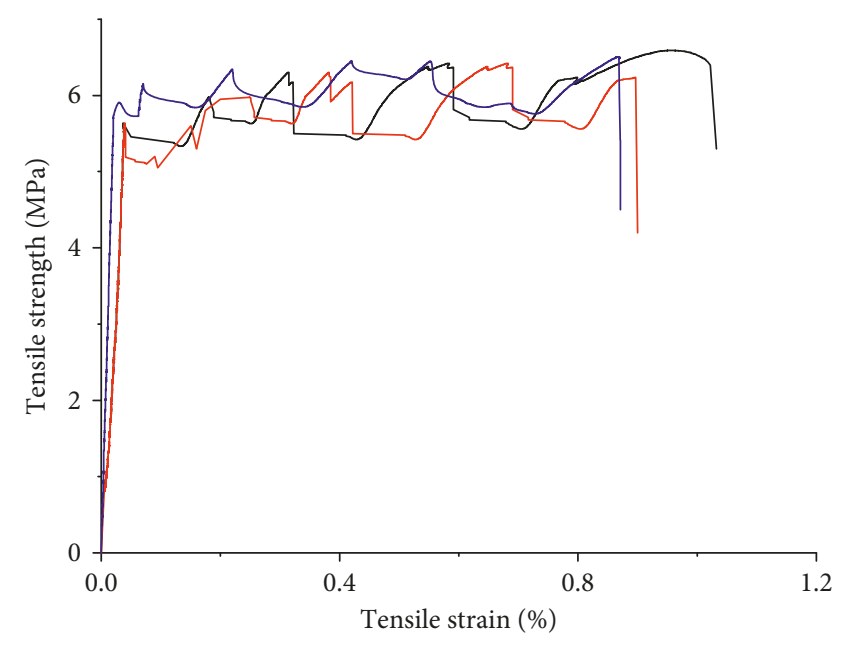

(a)

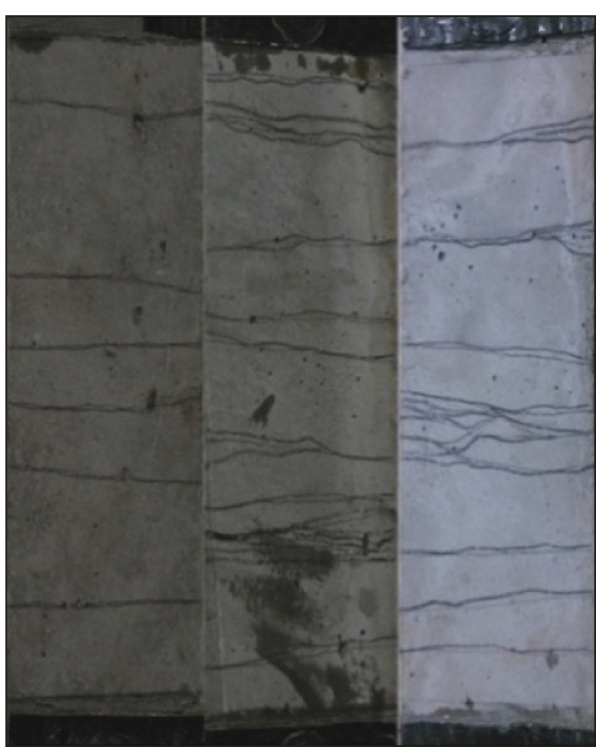

(b)

Figure 1: Stress-strain curves and the crack pattern of HDC. (a) Stress-strain curves and (b) crack pattern.

column were prepared to study the seismic performance of short columns under cyclic loading. The outcome of this paper would be helpful to demonstrate the advantages of fiber-reinforced cement composites like ECC and HDC compared with concrete.

\section{Experimental Programs}

2.1. HDC Materials. The mixed proportions of the HDC used in this study are summarized in Table 1. The components of HDC include binder (cement and fly ash), river sand, water, and polyvinyl alcohol (PVA) fibers. A 2\% volume incorporation of PVA fibers is used in the HDC, and the mechanical properties of the PVA fibers are shown in Table 2. Figure 1 shows the stress-strain curves and the crack pattern of HDC specimens in direct tension, which indicates that the average crack strength of HDC is $5.73 \mathrm{MPa}$, the average tensile strength is $6.14 \mathrm{MPa}$, and the ultimate tensile strain is about $1.0 \%$. In this paper, the tensile strength of HDC is conservatively taken as the cracking strength.

2.2. Specimen Design. Six HDC short columns and one RC short column employed as a control specimen were prepared. The columns had a cross section of $250 \mathrm{~mm} \times 250 \mathrm{~mm}$ with a height $H$ of $500 / 375 \mathrm{~mm}$, and the foundation beams had a cross section of $450 \mathrm{~mm} \times 450 \mathrm{~mm}$ with a total length of $1200 \mathrm{~mm}$. The longitudinal reinforcements for the short columns consisted of $6 \mathrm{HRB} 400(\mathrm{~d}=22 \mathrm{~mm})$ bars, while those for the foundation beams consisted of $8 \mathrm{HRB} 400(\mathrm{~d}=22 \mathrm{~mm})$ bars. Transverse reinforcements for the short columns and foundation beams consisted of $8 \mathrm{~mm}$ diameter hoops. As shown in Table 3, the key parameters of this study are the shear span ratio $\lambda=H / h$, the axial load $N$, and the stirrup spacing $s$.

Figure 2 shows the geometric size and reinforcement details of the specimens. The HDC material was cast in the connection of the foundation beams to avoid interface failure. The strengths of bars (yielding strength) and concrete and HDC (cubic compressive strength $f_{\mathrm{cu}}$ ) are listed in Table 4. The cubic compressive strength of concrete and HDC was tested by three cubic blocks $(100 \mathrm{~mm} \times 100 \mathrm{~mm} \times 100 \mathrm{~mm})$, respectively.

2.3. Test Equipment and Loading Procedure. The loading devices for the cyclic loading tests are shown in Figure 3. The constant vertical load was applied on the top of each column first through a hydraulic jack, and the lateral cycle load imposed on the columns was then applied by a $1000 \mathrm{kN}$ (MTS1000) hydraulic actuator. 
TABLE 3: Parameters of short columns.

\begin{tabular}{|c|c|c|c|c|c|c|}
\hline Specimen & Material & $\lambda$ & $H(\mathrm{~mm})$ & $s(\mathrm{~mm})$ & $\rho_{\text {sv }}$ & $N(\mathrm{kN})$ \\
\hline $\mathrm{RC1}$ & Concrete & 2 & 500 & 80 & $1.26 \%$ & 515.6 \\
\hline HDC2 & HDC & 2 & 500 & 80 & $1.26 \%$ & 343.7 \\
\hline HDC3 & $\mathrm{HDC}$ & 2 & 500 & 80 & $1.26 \%$ & 515.6 \\
\hline HDC4 & HDC & 2 & 500 & 80 & $1.26 \%$ & 687.5 \\
\hline HDC5 & HDC & 2 & 500 & 100 & $1.01 \%$ & 515.6 \\
\hline HDC6 & HDC & 2 & 500 & 120 & $0.84 \%$ & 515.6 \\
\hline HDC7 & HDC & 1.5 & 375 & 80 & $1.26 \%$ & 515.6 \\
\hline
\end{tabular}

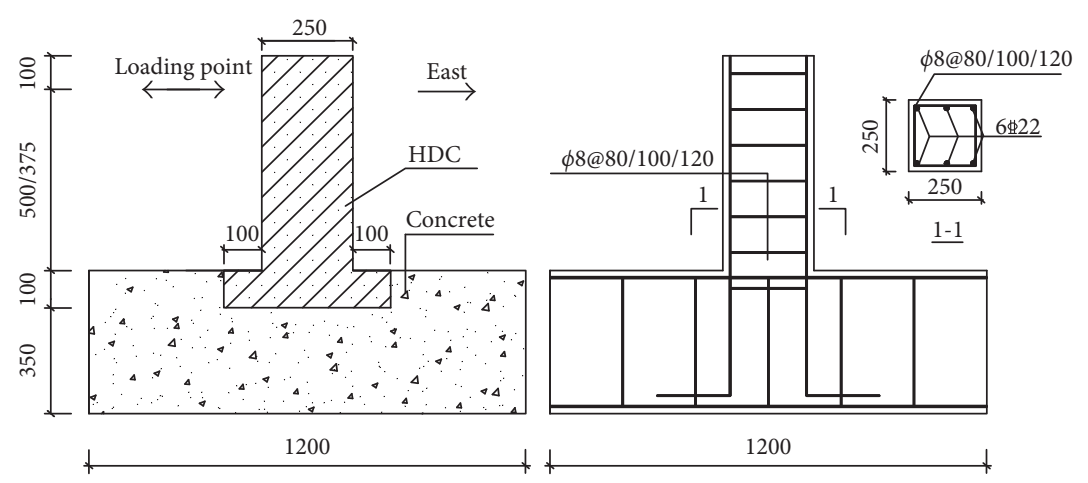

FIGURE 2: Geometry and reinforcement details (unit: $\mathrm{mm}$ ).

According to the Specification of Testing Methods for Earthquake Resistant Building [19] protocol, a forcedisplacement hybrid control program was used. Figure 4 shows the loading procedure of the test, which involved a force control step and a displacement control step. In the force control stage, the increment of lateral load was $20 \mathrm{kN}$ until the first yielding of the longitudinal steel bars during the tests. Then, the loading procedure was changed into the displacement control stage, and the increment of the displacement was $2 \mathrm{~mm}$; $n$ is the step number of displacement load. Each displacement load step was repeated thrice until the lateral load of the specimens dropped below $85 \%$ of the peak value.

2.4. Measurement and Data Acquisition. Figure 5 shows the installation position of the measurement devices on the short columns. A linear variable differential transducer (LVDT-1) was installed at the lateral loading point. The lateral slip of the foundation beam was monitored by LVDT-2. The shear deformation of each specimen was measured by two cross dial gauges located at the midheight of it. The strains in the longitudinal reinforcements and stirrups were measured using 24 strain foils attached on the reinforcement bars.

\section{Results and Analysis}

\subsection{Test Observation}

3.1.1. Specimen RC1. The cracking (a horizontal crack at the column foot) load of the control specimen RC1 was $80 \mathrm{kN}$.
TABLE 4: Strength of materials.

\begin{tabular}{lcccc}
\hline Material & HRB400 & HPB235 & Concrete & HDC \\
\hline Strength $(\mathrm{MPa})$ & 439 & 315 & 68.9 & 65.7 \\
\hline
\end{tabular}

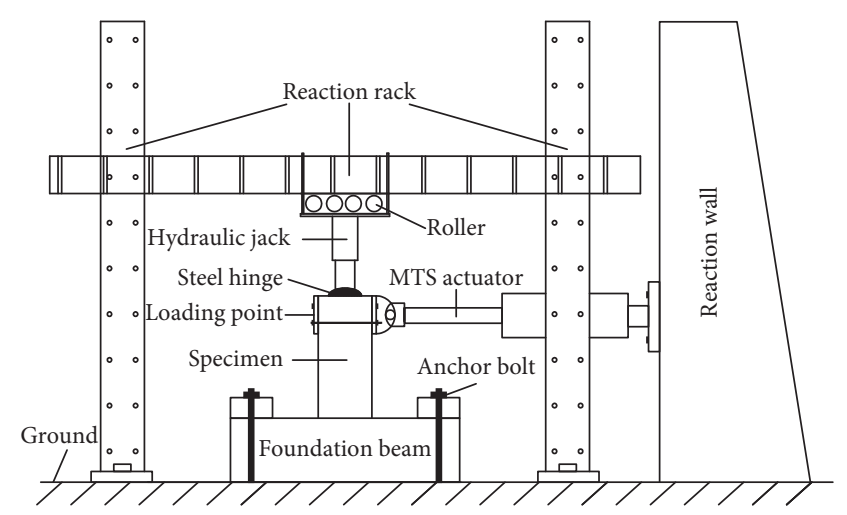

Figure 3: Test setup.

When the lateral load reached $140 \mathrm{kN}$, the first diagonal crack appeared in the midheight of the short column. The major diagonal cracks formed at a load equaled $220 \mathrm{kN}$ whilst the stirrups yielded. When the load reached $260 \mathrm{kN}$, the major diagonal crack widened to about $1 \mathrm{~mm}$ and the short column yielded; subsequently, the loading procedure was changed into the displacement control stage. When the displacement pulled to $8.5 \mathrm{~cm}$, specimen $\mathrm{RC1}$ reached its peak load $(299 \mathrm{kN})$. After that, the shear strength of RC1 declined sharply with the widening of the major diagonal 


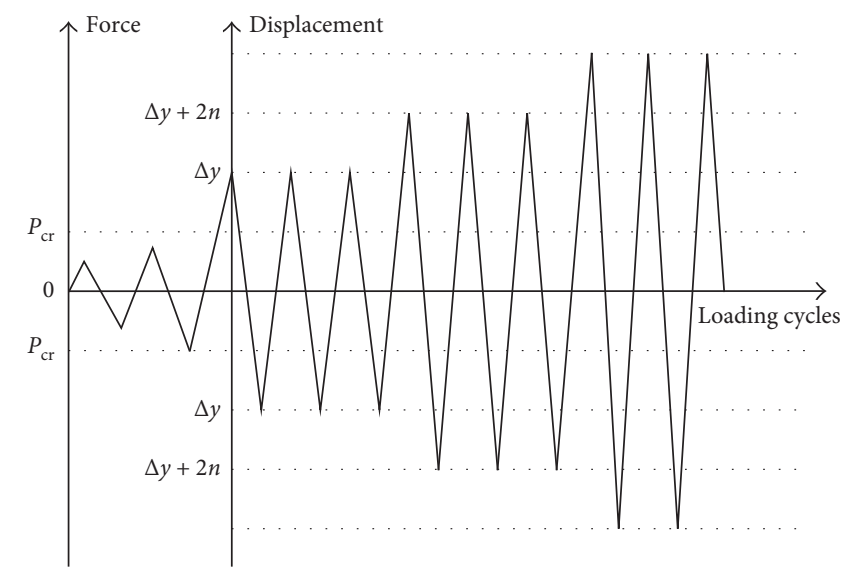

FIgURE 4: Loading procedure.

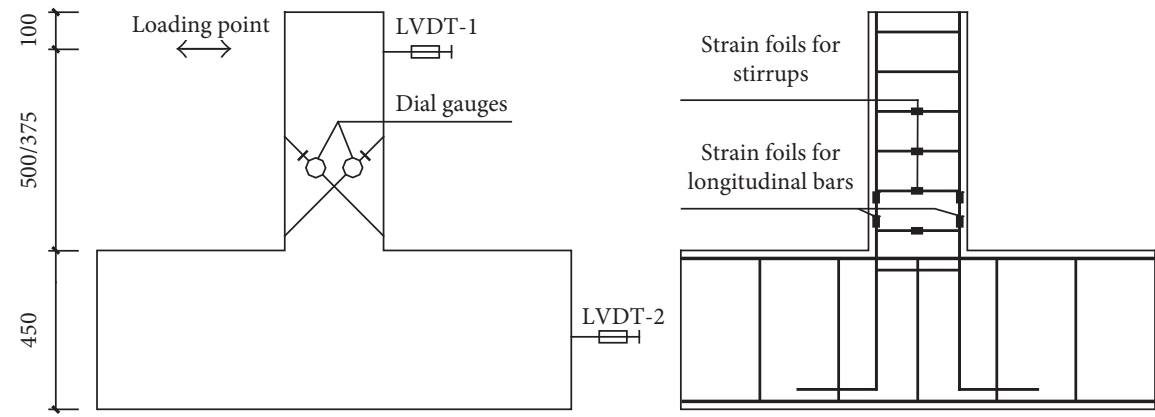

FIGURE 5: Measurement position.

cracks and the spalling of the concrete cover. No more cracks appeared with the process of cyclic loading. Finally, specimen RC1 failed in brittle shear with its concrete cover crushed and the steel bars exposed.

3.1.2. Specimen HDC3. For specimen HDC3, the stirrup ratio and axial load applied on it are the same with that for specimen RC1. The cracking (three horizontal cracks) load of the specimen was $130 \mathrm{kN}$, which was $50 \mathrm{kN}$ (62.5\%) higher than that of specimen RC1. When the lateral load equaled $180 \mathrm{kN}$, many tiny shear diagonal cracks appeared at the midheight of the specimen. The longitudinal reinforcements and stirrup yielded when the load increased to $280 \mathrm{kN}$; meanwhile, the horizontal cracks extending and diagonal cracks widening. Then, the displacement control loading was adopted. The peak load of specimen HDC3 was $366 \mathrm{kN}$ when the displacement pulled to $11.2 \mathrm{~mm}$, and a dense network of tiny cracks was observed near the major diagonal cracks. With the loading displacement increased, the lateral load decreased slower than that of specimen RC1. No crushing of the HDC cover was observed at the failure stage of the HDC short column, and the specimen failed in shear with moderate ductility.

The other HDC short columns behaved similar to specimen HDC3. Due to the fiber-bridging effect, HDC materials exhibited a higher tensile strength and higher toughness compared to concrete. As a result, the cracking loads of the HDC short columns were at least 50\% higher than those of the RC specimen, and no spalling of covers in HDC short columns occurred.

3.2. Crack Distribution and Failure Modes. Figure 6 shows the crack distribution of the short columns when longitudinal bars yield. X-shaped diagonal cracks and few horizontal cracks were observed in specimen RC1; however, a dense network of diagonal cracks appeared at the midheight of the HDC short columns with much smaller crack width than that of specimen $\mathrm{RC}$. This phenomenon is due to the multiple crack mechanism of HDC materials caused by the fiber-bridging effect. The angle between the diagonal crack and vertical axis decreased with the increase of axial load. With the decrease of stirrup ratio, the diagonal cracks became denser. In addition, the number of diagonal cracks decreased when the column had a smaller shear span ratio.

Figure 7 shows the final failure patterns of the short columns. For specimen RC1, the failure mode was dominated by shear at a drift of $1.8 \%$. Additionally, the concrete cover was severely crushed, and the reinforcement bars were exposed to the air, which indicates that specimen RC1 failed in brittle mode. While for the HDC short columns, even specimen HDC 6 (with the lowest stirrup ratio) reached a $2.8 \%$ drift at the failure stage, which is $55.5 \%$ higher than that of specimen RC1. Though significant X-shaped diagonal cracks were observed in HDC short columns, the dense 


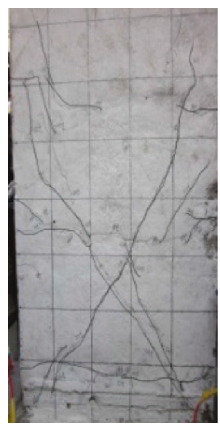

(a)

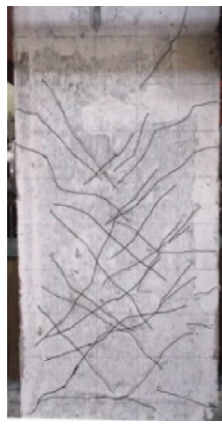

(b)

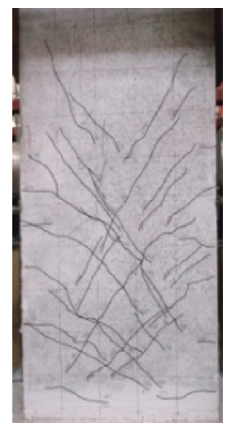

(c)

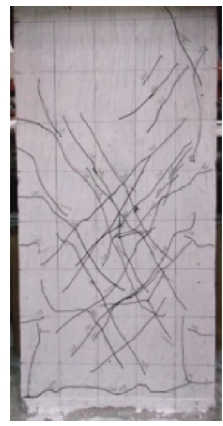

(d)

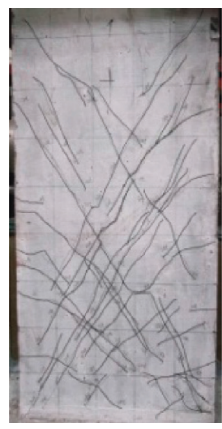

(e)

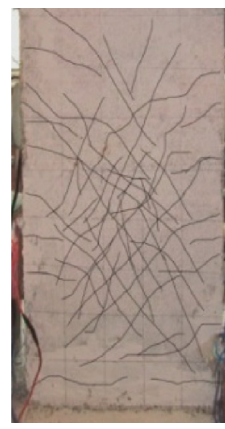

(f)

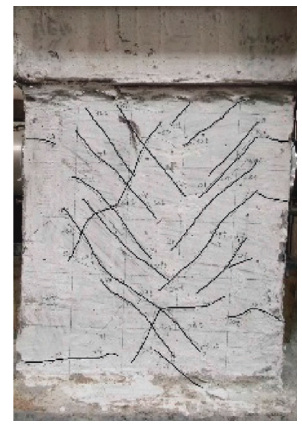

(g)

Figure 6: Crack distribution: (a) RC1, (b) HDC2, (c) HDC3, (d) HDC4, (e) HDC5, (f) HDC6, and (g) HDC7.



(a)

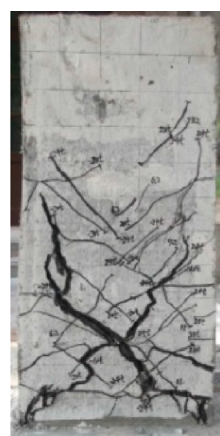

(b)

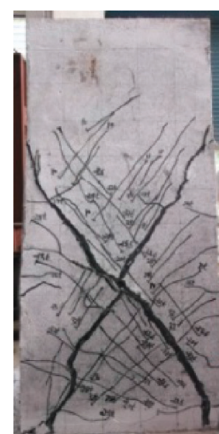

(c)



(d)

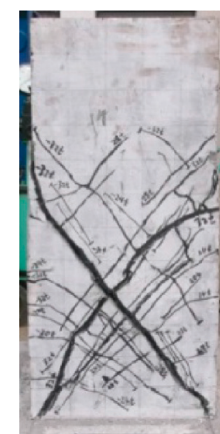

(e)

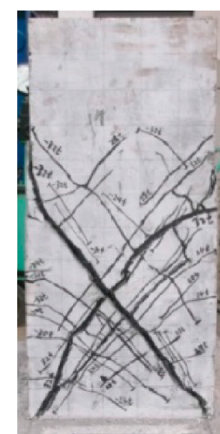

(f)

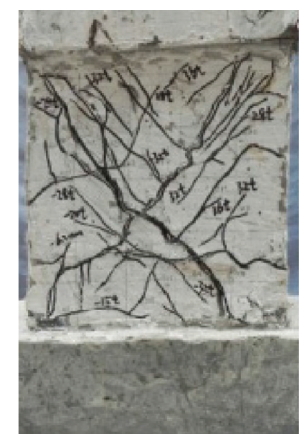

(g)

Figure 7: Final failure patterns: (a) RC1, (b) HDC2, (c) HDC3, (d) HDC4, (e) HDC5, (f) HDC6, and (g) HDC7.

network of diagonal cracks was distributed around the $\mathrm{X}$-shaped cross cracks, and the HDC short columns behaved much better in sustaining the intactness of the column section under the cyclic loading.

Compared with concrete, HDC exhibited excellent crack-controlling properties (multiple crack mechanism and strain-hardening behavior) due to the bridging effect of the PVA fibers. When the short columns cracked, the fibers between the cracks of HDC specimens could still transfer the tensile stress until the ultimate tensile strain. The behavior of the HDC short columns was dominated by shear because the design flexural capacity was relative high, but the ductility and the damage tolerance capacity of the short columns were effectively improved.

3.3. Hysteretic Behavior. Figure 8 shows the hysteretic curves of the short columns. It can be seen from this figure that the area of the hysteretic loops was small and narrow before cracking, which indicates that the columns were in the elastic state. After the cracking load, the lateral stiffness of each specimen decreased gradually due to the development of cracks, and the area of hysteretic loops increased. The peak load of each HDC short column was larger than that of specimen $\mathrm{RC} 1$ though the compressive strength of HDC was lower than that of concrete (in this study). After the peak load, the shear strength of specimen RC1 dropped rapidly, and the area of its hysteretic loops decreased at a high rate; however, the HDC short columns behaved much better in shear strength retention. Moreover, the HDC short columns were able to suffer more cycles of lateral loading than specimen RC1; thus, the HDC short columns had much larger amounts of hysteretic loops, namely, higher energy dissipation capacity, which is very favorable for earthquake resistance.

The hysteretic loops of HDC short columns were similar in shapes. With the increase of the axial load and the stirrup spacing, the area of the hysteretic loops of HDC short columns became narrower. When the HDC short column had a smaller shear span ratio, the area of the hysteretic loops decreased.

3.4. Skeleton Curves and Performance Indexes. Figure 9 shows the skeleton curves of the specimens, and Table 5 lists the characteristic loads (i.e., the crack load $P_{\text {cr }}$, yield load $P_{y}$, peak load $P_{m}$, and ultimate load $P_{u}$ ) and their corresponding displacements obtained from Figure 9. The yield loads of the short columns are defined by the energy method proposed by Mahin and Bertero [20], and the ultimate loads equal to the lateral loads decline to $85 \%$ of their peak value. The displacement ductility factor $\mu=\Delta_{u} / \Delta_{y}$ and the ultimate 


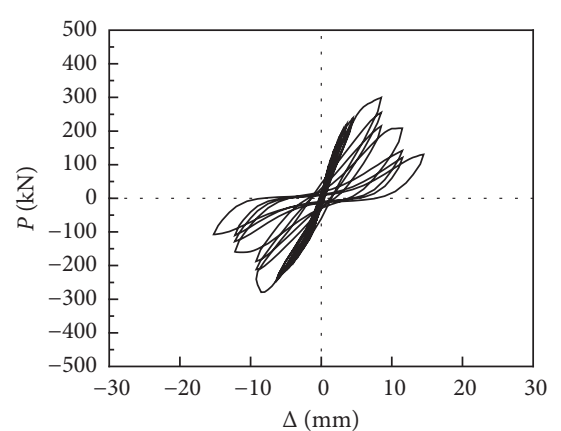

(a)

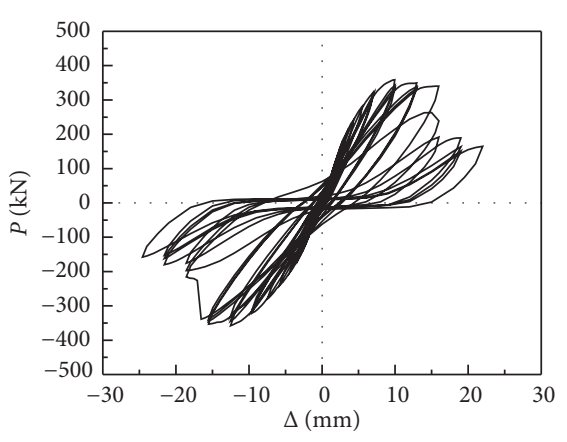

(c)

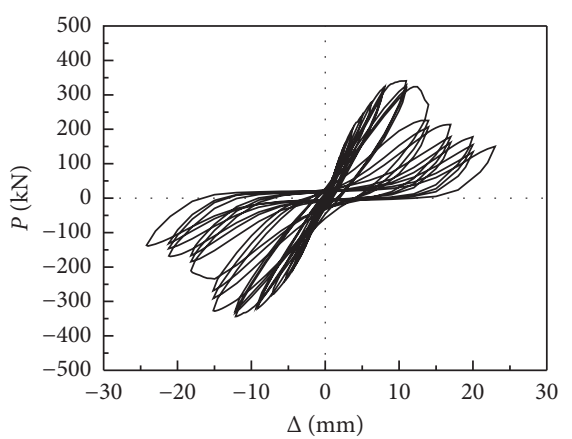

(e)

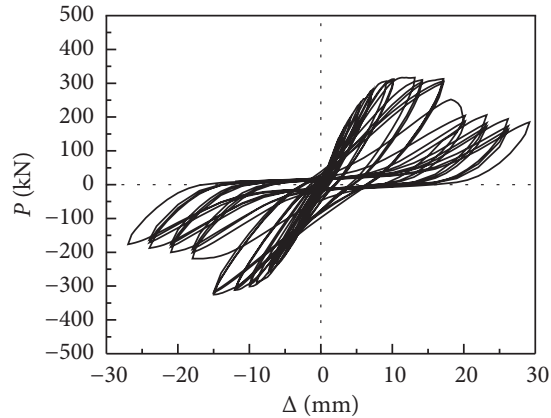

(b)

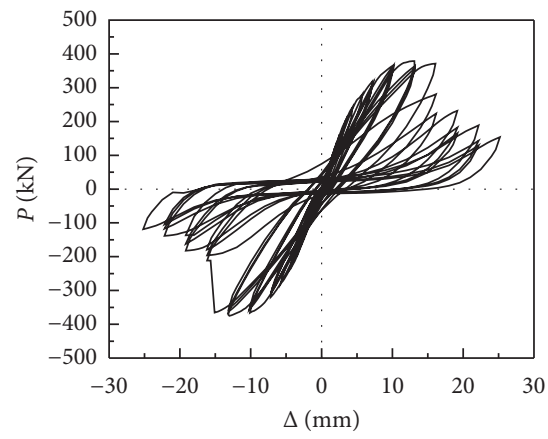

(d)

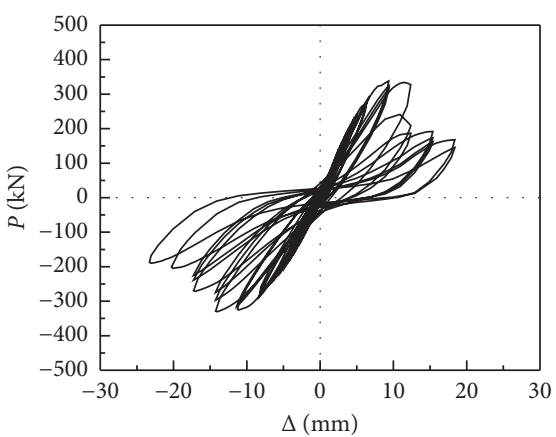

(f)



(g)

Figure 8: Hysteretic loops of specimens: (a) specimen RC1, (b) specimen HDC2, (c) specimen HDC3, (d) specimen HDC4, (e) specimen HDC5, (f) specimen HDC6, and (g) specimen HDC7. 




(a)

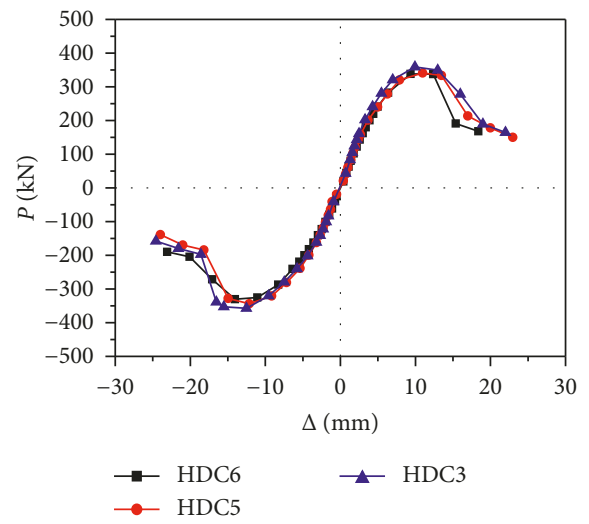

(c)

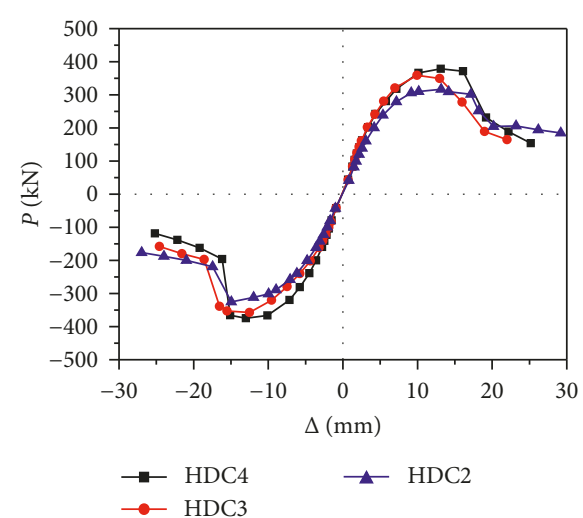

(b)

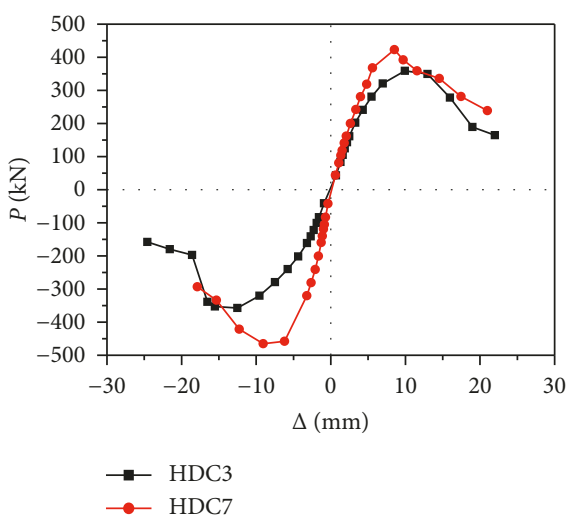

(d)

FIgURE 9: Skeleton curves of specimens: (a) effect of the material, (b) effect of the axial load ratio, (c) effect of the stirrup ratio, and (d) effect of the shear span ratio.

TABle 5: Comparisons of the characteristic load and displacement.

\begin{tabular}{lccccccccc}
\hline Specimen & $P_{\mathrm{cr}}(\mathrm{kN})$ & $\Delta_{\mathrm{cr}}(\mathrm{mm})$ & $P_{y}(\mathrm{kN})$ & $\Delta_{y}(\mathrm{~mm})$ & $P_{m}(\mathrm{kN})$ & $\Delta_{m}(\mathrm{~mm})$ & $\Delta_{u}(\mathrm{~mm})$ & $\theta_{u}=\Delta_{u} / H$ & $\mu=\Delta_{u} / \Delta_{y}$ \\
\hline RC1 & 80 & 0.90 & 240.05 & 5.42 & 289.49 & 8.51 & 9.17 & $1 / 55$ \\
HDC2 & 120 & 2.39 & 268.51 & 7.12 & 326.05 & 13.65 & 17.29 & $1 / 29$ & 2.49 \\
HDC3 & 130 & 2.24 & 270.62 & 6.65 & 358.20 & 11.23 & 15.43 & $1 / 32$ & 2.32 \\
HDC4 & 150 & 2.54 & 318.83 & 7.16 & 376.85 & 13.06 & 16.20 & $1 / 31$ & 2.26 \\
HDC5 & 130 & 2.34 & 279.74 & 6.72 & 342.39 & 11.55 & 14.39 & $1 / 35$ \\
HDC6 & 140 & 2.79 & 261.31 & 6.38 & 334.26 & 11.71 & 14.48 & $1 / 35$ & 2.27 \\
HDC7 & 150 & 1.81 & 394.01 & 5.73 & 443.92 & 7.37 & 13.89 & $1 / 27$ & 2.75 \\
\hline
\end{tabular}

drift ratio $\theta_{u}=\Delta_{u} / H$ are used to evaluate the ductility and deformation capacity of the short columns, as shown in Table 5. Based on Figure 9 and Table 5, the following observations can be drawn:

(1) The axial load and stirrup ratio of specimen HDC3 were the same with those of specimen RC1. The peak load of specimen HDC3 was 24\% higher, and the lateral load decreased at a slower rate than that of specimen RC1 (Figure 9(a)). Both (RC1 and HDC3) failed in shear, the displacement ductility factor of specimen HDC3 increased by $37 \%$, and the ultimate drift ratio increased by $72 \%$. It means that using HDC can significantly improve the plastic deformation ability of short columns.

(2) The peak loads of HDC short columns increased with the rise of axial load, while there were no big differences in the ultimate drift ratios and displacement ductility factors of HDC2, HDC3, and HDC4, indicating that the influence of axial load on the ductility and deformation capacity of HDC short columns is relatively small.

(3) Compared with specimen RC1, the peak load, displacement ductility factor, and ultimate drift ratio of 
specimen HDC6 were improved by $15.5 \%, 34.3 \%$, and $57.9 \%$, respectively, which indicates that using HDC to replace concrete can significantly reduce the stirrup ratio.

(4) Compared with specimen HDC3, the stirrup ratio of specimens HDC5 and HDC6 was reduced by $20 \%$ and $33 \%$, respectively, while the peak loads of specimens HDC5 and HDC6 were only reduced by $4.4 \%$ and $6.6 \%$, respectively; meanwhile, the displacement ductility factor of specimens HDC5 and HDC6 was reduced by $7.7 \%$ and $2.1 \%$, respectively, which means that the influence of the stirrup ratio on the shear strength and ductility of HDC short columns is relatively small. Additionally, the ultimate drift ratio of specimen HDC5 was about $57 \%$ higher that of specimen RC1, which again certified that using HDC to replace concrete could reduce the amount of the stirrups.

(5) The shear strength of specimen HDC7 was 23.9\% higher than that of specimen HDC3. Besides, the ultimate drift ratio and the displacement ductility factor of specimen HDC7 are $18.5 \%$ and $18.5 \%$ higher than those of specimen HDC3, respectively, which indicates that HDC can be used to improve the strength and deformation capacity of high shear stress components.

Above all, using HDC to replace concrete in short columns can greatly enhance their shear strength and deformation capacity and also reduce the stirrup ratio due to the significant tensile performance of HDC, namely, the strain-hardening behavior due to the fiber-bridging effect. These results indicate that the ductility of the HDC material achieves the ductility of the structural members.

3.5. Energy Dissipation Capacity. The energy dissipation capacity of the specimens under cyclic loading is an important indicator to evaluate the seismic behavior of short columns. In lateral reversed cyclic loading tests, the energy dissipation capacity can be reflected by the cumulative energy absorption at characteristic points, which are the yield point, peak point, and ultimate point. Table 6 shows the cumulative energy dissipation at the characteristic points mentioned above. It can be seen that

(1) the HDC short columns exhibited a significant increase in cumulative energy dissipation in comparison to RC1 ranging between $109 \%$ and $239 \%$ at the yield displacement, and from $134 \%$ to $247 \%$ at the peak displacement, and from $181 \%$ to $337 \%$ at the ultimate displacement, indicating that using HDC to replace concrete could improve the cumulative energy dissipation of short columns tremendously, especially when the specimens were in the failure stage;

(2) the cumulative energy dissipation by specimen HDC3 at the yield load, peak load, and ultimate load were 2.39 times, 2.02 times, and 2.9 times higher than that by specimen $\mathrm{RC} 1$, respectively, which means that the energy dissipation capacity of short columns
TABLE 6: Energy dissipation of short columns.

\begin{tabular}{lccc}
\hline \multirow{2}{*}{ Specimen } & \multicolumn{3}{c}{ Accumulated energy dissipation $(\mathrm{kN} \cdot \mathrm{mm})$} \\
& $\Delta_{y}$ & $\Delta_{m}$ & $\Delta_{u}$ \\
\hline RC1 & 241.63 & 1581.07 & 3547.57 \\
HDC2 & 747.54 & 5492.02 & $15,494.21$ \\
HDC3 & 819.38 & 4782.07 & $13,868.88$ \\
HDC4 & 748.34 & 4204.59 & $12,331.63$ \\
HDC5 & 900.75 & 4363.54 & $12,158.34$ \\
HDC6 & 720.46 & 4251.20 & $11,981.61$ \\
HDC7 & 506.12 & 3713.31 & 9997.16 \\
\hline
\end{tabular}

at different performance levels can be improved considerably by replacing concrete with HDC;

(3) the energy dissipation capacity of HDC short columns at different displacements decreased with the rise of axial load ratio while increased with the rise of stirrup ratio. Even specimen HDC7 with a smaller shear span ratio dissipated more energy than that of specimen RC1, which indicates that the energy dissipation capacity of the HDC short columns is mainly dominated by the properties of the HDC materials.

3.6. Stiffness Degradation. The secant stiffness $K_{i}$ is used to analyze the stiffness degradation of the short columns, which is defined as the slope of the line from the origin of coordinates to the peak load of each (ith) cycle:

$$
K_{i}=\frac{\left|+P_{i}\right|+\left|-P_{i}\right|}{\left|+\Delta_{i}\right|+\left|-\Delta_{i}\right|},
$$

where $+P_{i}$ and $-P_{i}$ are the peak load of the $i$ th cycle in pushing and pulling, respectively, and $+\Delta_{i}$ and $-\Delta_{i}$ are the corresponding displacement to $+P_{i}$ and $-P_{i}$. The stiffness degradation curves of the short columns are shown in Figure 10. It can be concluded from Figure 10 that

(1) as the elasticity modulus of HDC is lower than that of the concrete, the initial stiffness of HDC3 is lower than that of RC1. The initial stiffness of HDC short columns increases with the rise of axial load ratio, while the stirrup ratio has little effect on the initial stiffness. Besides, the initial stiffness of the HDC short column increases significantly with the decrease of shear span ratio;

(2) under the cyclic loading, the lateral stiffness of specimen RC1 decreased rapidly due to the development of cracks and the softening of concrete. In contrast, the lateral stiffness of the HDC short columns decreased much slower than that of RC1 due to the strain-hardening behavior of HDC materials. Namely, the fiber-bridging effect between the diagonal cracks effectively sustained the shear strength of the cracked HDC short columns;

(3) HDC is a material with high compressive toughness and shear deformation ability; thus, the influence of 




(a)

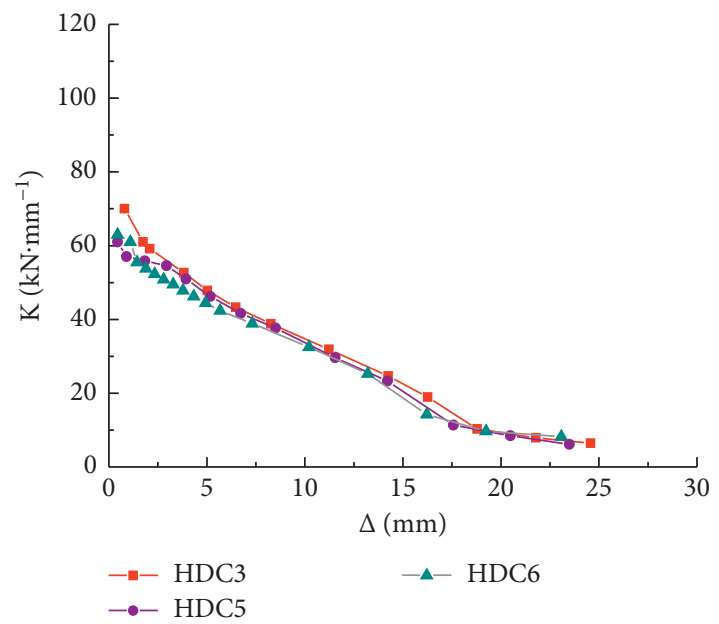

(c)

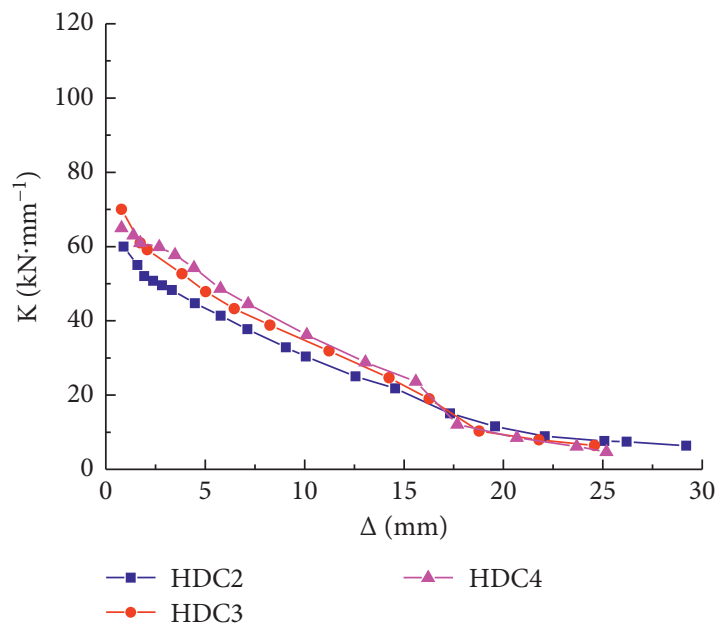

(b)

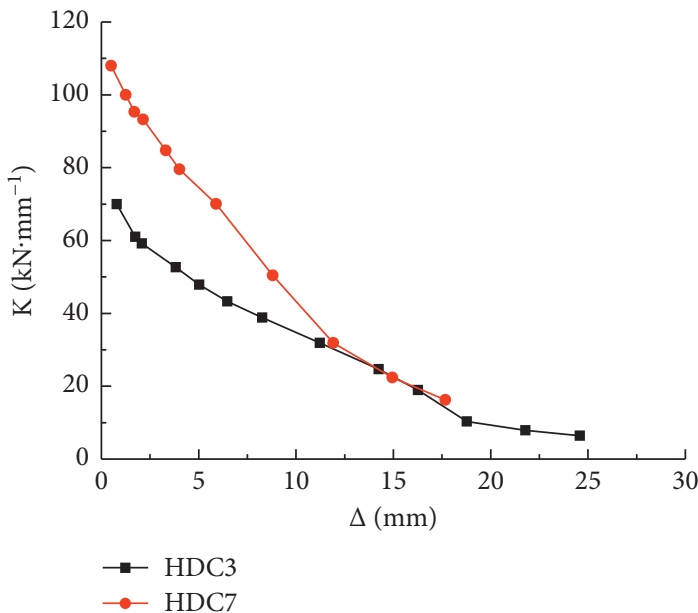

(d)

Figure 10: Curves of stiffness degradation: (a) effect of the material, (b) effect of the axial load ratio, (c) effect of the stirrup ratio, and (d) effect of the shear span ratio.

the axial load and stirrup ratio on the stiffness degradation rate is relatively small. However, the stiffness degradation rate is much higher when the shear span ratio becomes smaller.

\section{Shear Strength}

Most current design codes such as ACI 318 [21] and GB 500102010 [22] consider that the shear strength $V_{n}$ of RC columns consists of concrete shear contribution $V_{c}$ and transverse stirrup shear contribution $V_{c}$. The calculation formulas of the ACI 318 model and GB 50010-2010 proposal can be expressed as (2) and (3), respectively, and the effect of axial load on the shear strength in these two models is considered:

$$
\begin{aligned}
& V_{n}=V_{c}+V_{s}=0.17\left(1+\frac{N}{14 A}\right) \sqrt{f_{c}^{\prime}} b h_{0}+\frac{A_{\mathrm{sv}} f_{\mathrm{yv}} h_{0}}{s}, \\
& V_{n}=V_{c}+V_{s}=\frac{1.75}{\lambda+1} f_{t} b h_{0}+\frac{A_{\mathrm{sv}} f_{\mathrm{yv}} h_{0}}{s}+0.07 N .
\end{aligned}
$$

TABLE 7: Test results and calculated results $(\mathrm{kN})$.

\begin{tabular}{lccccc}
\hline Specimen & $P_{m}$ & $V_{n}(\mathrm{ACI})$ & $P_{m} / V_{n}(\mathrm{ACI})$ & $V_{n}(\mathrm{~GB})$ & $P_{m} / V_{n}(\mathrm{~GB})$ \\
\hline RC1 & 289.5 & 206.5 & 1.40 & 258.0 & 1.12 \\
HDC2 & 326.0 & 196.2 & 1.66 & 301.1 & 1.08 \\
HDC3 & 358.2 & 212.5 & 1.68 & 313.1 & 1.14 \\
HDC4 & 376.9 & 228.7 & 1.64 & 325.2 & 1.16 \\
HDC5 & 342.4 & 194.7 & 1.76 & 295.3 & 1.16 \\
HDC6 & 334.3 & 182.8 & 1.82 & 283.5 & 1.18 \\
HDC7 & 443.9 & 212.5 & 2.08 & 350.7 & 1.26 \\
\hline
\end{tabular}

According to GB 50010-2010, the cylinder compressive strength, the axial compressive strength, and the tensile strength of the concrete are calculated based on the relationships $f_{c}^{\prime}=0.8 f_{\mathrm{cu}}, f_{c}=0.76 f_{\mathrm{cu}}$, and $f_{t}=0.395 f_{\mathrm{cu}}^{0.55}$, 
respectively. Equations (2) and (3) are used to predict the shear strength of ordinary RC columns, and the effectiveness of the formulas mentioned above for calculating the shear strength of HDC short columns is not known. The test results and the calculated results based on (2) and (3) are listed in Table 7.

As shown in Table 7, the results calculated by (2) are at least $40 \%$ smaller than the test results. This is because the ACI 318 calculating model does not take into account the effect of the shear span ratio and the tensile stress transferred by the fiber between the diagonal cracks. The results calculated by (3) agree better with the test results compared with (2). However, the results calculated by (3) are still 8-26\% lower than the test values. This is because the GB 50010-2010 calculating model does not take into account the dowel action of the longitudinal bars (the longitudinal reinforcement ratio of the short columns is 3.65\%). In all, the calculating model of GB 50010-2010 can be adopted to predict the shear strength of the HDC short columns safely.

\section{Conclusions}

Based on the results and analysis obtained by the cyclic loading tests, the following conclusions can be made:

(1) The failure mode of RC short columns was dominated by brittle shear, while the HDC short columns failed in relatively ductile shear with the dense network of diagonal cracks observed. Severe crushing of the concrete cover occurred in RC short columns at the failure stage, while the HDC short columns effectively sustained the intactness of the column section due to the fiber-bridging effect in HDC materials.

(2) Compared with the RC short column, the hysteretic performance of the HDC short columns was significantly improved, and the HDC short columns were able to suffer more cycles of lateral loading and dissipate more earthquake energy than those of the RC specimen before failure. At the ultimate displacement, the cumulative energy dissipation of the HDC short column was at least $237 \%$ higher than that of the RC specimen, which is very favorable for earthquake resistance.

(3) Using HDC to replace concrete in short columns could significantly enhance the crack load and the peak load and also considerably improve the displacement ductility factor and the ultimate drift ratio of the specimens. The increase of ultimate drift ratio of HDC short columns was at least $56.9 \%$ compared with the RC short column, which means that there is effective improvement in the plastic deformation capacity of the short columns.

(4) The influence of the axial load on the deformation capacity and the energy dissipation capacity of HDC short columns is relatively small. The ultimate drift ratio and energy dissipation capacity of the columns mainly depend on the property of the HDC materials. When the column has a smaller shear span ratio, the energy dissipation capacity decreased but the ultimate drift ratio increased.

(5) Under the lateral cyclic loading, the lateral stiffness of the RC short column decreases rapidly due to the crack opening and concrete softening. In contrast, the lateral stiffness of the HDC short columns decreases relatively slower than that of the RC specimen due to the good tensile behavior of the HDC materials. Namely, the fiber-bridging effect between the cracks effectively sustains the shear strength of the cracked HDC short columns.

(6) The shear strength of HDC short columns predicted based on the GB 50010-2010 method agrees well with the test results; thus, the proposed method can be safely used in the design of HDC short columns.

\section{Nomenclature}

$H$ : $\quad$ Height of the column

$\rho_{s}$ : Longitudinal reinforcement ratio

$b$ : Column width

$\rho_{\text {sv }}: \quad$ Stirrup ratio

$h$ : $\quad$ Column depth

$P_{\text {cr }}, \Delta_{\text {cr }}$ : Crack load, crack displacement

$h_{0}$ : $\quad$ Effective column depth

$P_{y}, \Delta_{y}$ : Yield load, yield displacement

$\lambda$ : $\quad$ Shear span ratio

$P_{m}, \Delta_{m}$ : Peak load, peak displacement

$s: \quad$ Stirrup spacing

$\Delta_{u}: \quad$ Ultimate displacement

$f_{t}$ : Tensile strength of concrete

$\mu$ : $\quad$ Displacement ductility factor

$f_{y}$ : Yield strength of longitudinal bars

$\theta_{m}: \quad$ Peak drift ratio

$f_{\mathrm{yv}}: \quad$ Yield strength of stirrups

$\theta_{u}: \quad$ Ultimate drift ratio

$f_{\mathrm{cu}}$ : Cube compressive strength of concrete

$A$ : $\quad$ Cross section area of the column

$f_{c}^{\prime}$ : Cylinder compressive strength of concrete

$A_{\text {sv }}$ : Total cross section area of stirrups

$f_{c}$ : Axial compressive strength of concrete

$V_{n}: \quad$ Nominal shear strength

$N$ : $\quad$ Axial load on the top of the column

$V_{c}, V_{s}$ : Shear strength of concrete, stirrup.

\section{Conflicts of Interest}

The authors declare that there are no conflicts of interest regarding the publication of this paper.

\section{Acknowledgments}

The research was funded by the National Natural Science Foundation of China (Grant no. 51578445) and the Project of Department of Construction of Shanxi Province (no. 2015-K142), which is gratefully acknowledged. 


\section{References}

[1] M. L. Moretti and T. P. Tassios, "Seismic behavior of R-C short columns," in Proceedings of the 11th European Conference on Earthquake Engineering, Paris, France, 1998.

[2] R. Jiang, S. L. Xu, and J. Q. Jia, "An experimental study on the seismic ductility of PVA fiber super-high-strength concrete columns with high axial load ratio," China Civil Engineering Journal, vol. 40, no. 8, pp. 54-60, 2007, in Chinese.

[3] R. Jiang, "Experimental study on ductility of steel fiber superhigh-strength concrete short columns under high axial load ratio," Journal of Building Structures, vol. 28, pp. 230-235, 2007, in Chinese.

[4] J. L. Kou, M. K. Deng, and X. W. Liang, "Experimental study of uniaxial tensile properties of ductile fiber reinforced concrete," Building Structure, vol. 43, no. 1, pp. 59-64, 2013, in Chinese.

[5] M. K. Deng, J. Han, H. B. Liu, M. Qin, and X. Liang, “Analysis of compressive toughness and deformability of high ductile fiber reinforced concrete," Advances in Materials Science and Engineering, vol. 2015, Article ID 384902, 7 pages, 2015.

[6] V. C. Li, S. Wang, and C. Wu, "Tensile strain-hardening behavior of PVA-ECC," ACI Materials Journal, vol. 98, no. 6 , pp. 483-492, 2001.

[7] V. C. Li, "On engineered cementitious composites (ECC): a review of the material and its applications," Journal of Advanced Concrete Technology, vol. 1, no. 3, pp. 215-230, 2003.

[8] G. J. Parra-Montesinos, "High-performance fiber-reinforced cement composites: an alternative for seismic design of structures," ACI Structural Journal, vol. 102, no. 5, pp. 668-675, 2005.

[9] G. J. Parra-Montesinos, H. W. Reinhardt, and A. E. Naaman, High Performance Fiber Reinforced Cement Composites 6, Springer, Netherlands, 2012.

[10] K. Shimizu, T. Kanakubo, T. Kanda, and S. Nagai, "Shear behavior of steel reinforced PVA-ECC beams," in Proceedings of the 13th World Conference on Earthquake Engineering, Vancouver, British Columbia, Canada, August 2004.

[11] R. Zhang, K. Matsumoto, T. Hirata, Y. Ishizeki, and J. Niwa, "Shear behavior of polypropylene fiber reinforced ECC beams with varying shear reinforcement ratios," Journal of JSCE, vol. 2, no. 1, pp. 39-53, 2014.

[12] M. K. Deng, J. Dai, H. S. Lu, and X. W. Liang, "Shear capacity and failure behavior of steel reinforced high ductile concrete beams," Advances in Materials Science and Engineering, vol. 2015, Article ID 845490, 8 pages, 2015.

[13] S. Qudah and M. Maalej, "Application of Engineered Cementitious Composites (ECC) in interior beam-column connections for enhanced seismic resistance," Engineering Structures, vol. 69, no. 9, pp. 235-245, 2014.

[14] S. H. Said and H. A. Razak, "Structural behavior of RC engineered cementitious composite (ECC) exterior beamcolumn joints under reversed cyclic loading," Construction and Building Materials, vol. 107, pp. 226-234, 2016.

[15] M. D. Lepech and V. C. Li, "Application of ECC for bridge deck link slabs," Materials and Structures, vol. 42, no. 9, pp. 1185-1195, 2009.

[16] A. Dehghani, G. Fischer, and F. N. Alahi, "Strengthening masonry infill panels using engineered cementitious composites," Materials and Structures, vol. 48, no. 1-2, pp. 185204, 2015.

[17] M. A. Kyriakides and S. L. Billington, "Behavior of unreinforced masonry prisms and beams retrofitted with engineered cementitious composites," Materials and Structures, vol. 47, no. 9, pp. 1573-1587, 2014.

[18] C. Wu, Z. Pan, R. K. L. Su, C. K. Y. Leung, and S. Meng, "Seismic behavior of steel reinforced ECC columns under constant axial loading and reversed cyclic lateral loading," Materials and Structures, vol. 50, no. 1, p. 78, 2016.

[19] JGJ 101-2015, Specification of Testing Methods for Earthquake Resistant Building, China Building Industry Press, Beijing, China, 2015, in Chinese.

[20] S. A. Mahin and V. V. Bertero, "An evaluation of inelastic seismic design spectra," Journal of Structural Engineering, vol. 107, no. 9, pp. 1775-1795, 1981.

[21] ACI Committee 318, Building Code Requirements for Structural Concrete and Commentary (ACI 318-05), American Concrete Institute, Farmington Hills, MI, USA, 2005.

[22] GB 50010-2010, Code for Design of Concrete Structures, Chinese Building Press, Beijing, China, 2010, in Chinese. 


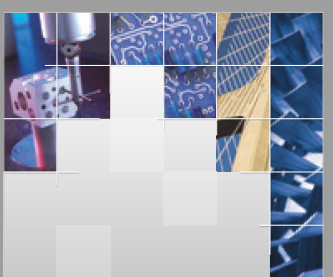

\section{Enfincering}
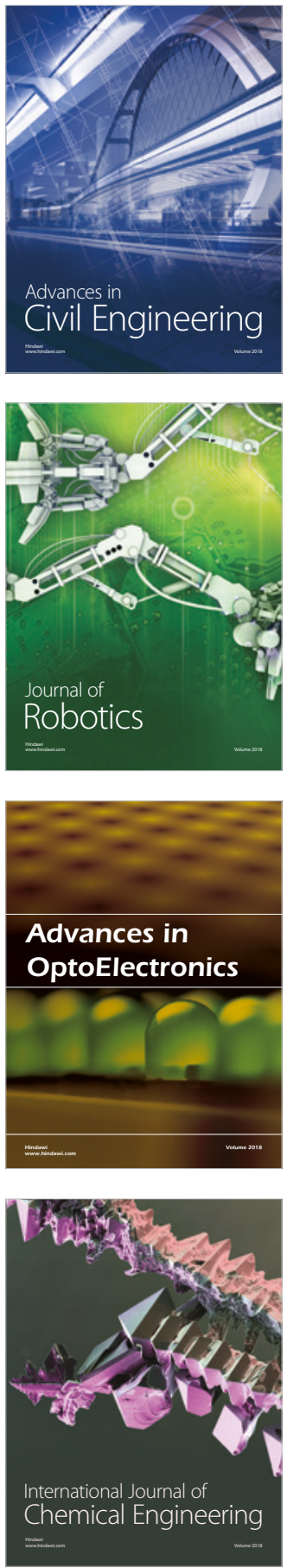

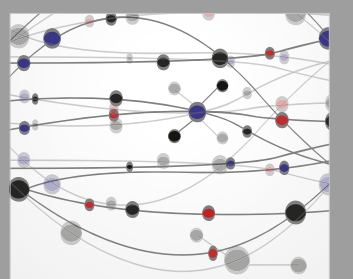

\section{Rotating \\ Machinery}

The Scientific World Journal

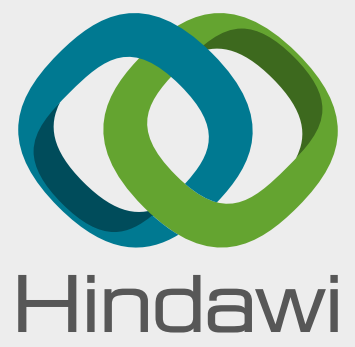

Submit your manuscripts at

www.hindawi.com

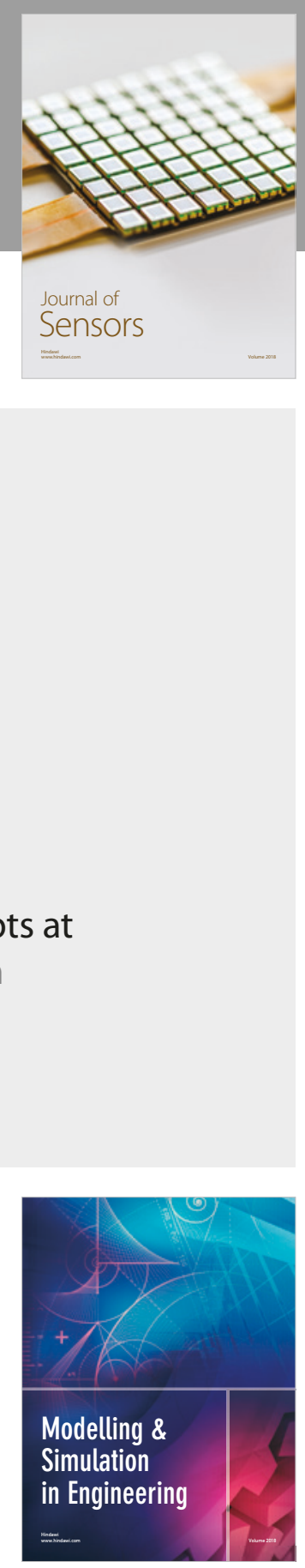

\section{Advances \\ Multimedia}
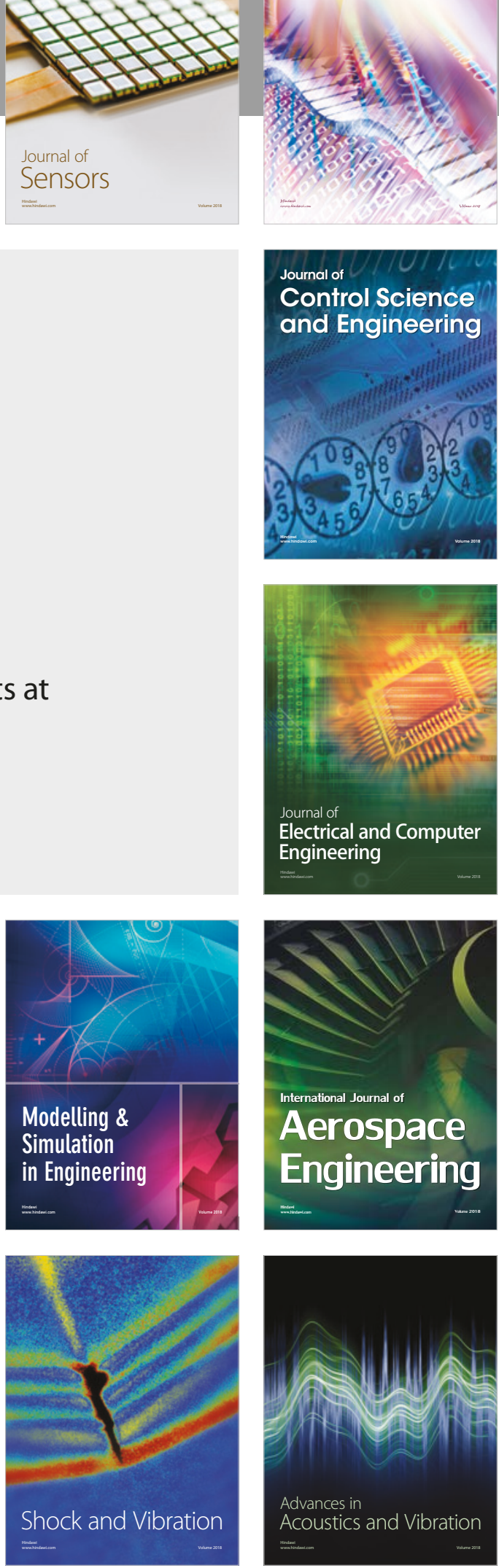